\title{
Biology of white grub Anomala dimidiata (Hope) (Coleoptera: Scarabaeidae) in agricultural ecosystem, Doon Valley, (U.K.), India
}

\author{
Sharma,Pushpendra,K. ${ }^{1}$, Shah,Mukesh,L. ${ }^{1}$ Mishra,Anup,K. ${ }^{2}$
}

Received: 25.03.2021

Revised: 05.05.2021

Accepted: 15.05.2021

\begin{abstract}
Present study was carried out to know the biology of white grub Anomala dimidiata (Hope) (Coleoptera: Scarabaeidae) collected from agricultural ecosystem with reference ecological conditions of Doon Valley. Anomala dimidiata (Hope) is a dominant species among the scarabaeid beetles and commonly distributed throughout India. Emergence of beetle is begun at the end of May when first pre-monsoon rain occurred, but peak emergence was observed in the second and third week of July after heavy rainfall. Maximum numbers of beetles were trapped during second and third week of July. Grubs were found throughout the year, causing severe damage to host plants. The males of this species show marked territorial behavior and chase the intruding conspecific females. During the study period, it was observed that the eggs are elongated, cylindrical and laid in clusters in. The observed copulation period was $40.0 \pm 14.14$ min. The oviposition period was 8.0 \pm 1.41 days. The incubation period of eggs was $14.60 \pm 0.72$ days. Larval period remained for 248 to 278 days. The pupal stage lasts for $14.70 \pm 0.62$ days. The adult female is broadly oval, less convex shape and slightly larger than male. The stage lasts for $27.75 \pm 4.74$ days.
\end{abstract}

Key words: Biology, White Grub, Anomala dimidiata, Agricultural Ecosystem

\section{Introduction}

The family Scarabaeidae is one of the largest, most diverse and widely distributed families of the largest order Coleoptera. The family Scarabaeidae includes about 27,800 species worldwide (Jameson $\&$ Ratcliffe, 2001). There are about more than 1500 species of white grubs have been reported from various parts of India. Among these species Anomala dimidiata (Hope), Holotrichia longipennis (Blanch.), Holotrichia seticollis (Moser), Brahmina coriacea (Hope), Holotrichia serrata (Fab.) and Lepidiota mansueta (Bur.) are wide spread (Chandel et al., 2015). Thirty-five species of white grub beetles have been reported by worker from Doon Valley, Uttarakhand (Lal, 2018). Out of these 35 species, 22 species reported from agricultural ecosystem (Lal and Sharma, 2017a) and 19 species from forest ecosystem of Doon Valley (Lal and Sharma, 2017b). Scarabaeids are polyphagous pest both in the grub and adult stage inflicting heavy damage on various fruit/ forest trees, their

\section{Author's Address}

${ }^{1}$ Department of Zoology, D.A.V. (P.G.) College, Dehradun(U.K.), India

${ }^{2}$ Department of Botany, D.A.V. (P.G.) College, Dehradun(U.K.), India

E-mail.: insect1980@rediffmail.com nurseries, vegetables, lawns and field crops (Chandel and Kashyap, 1997). The white grubs are destructive and troublesome insect pest all over the world. In India, white grubs (Coleoptera: Scarabaeidae) popularly known as root grubs have attained the status of a serious pest. Anomala dimidiata (Hope) is considered most destructive (Lal, 2018). In Uttarakhand, the beetles are phytophagous and defoliate fruits and forest trees during the rainy season, while the grubs are subterranean and have attained the status of a major devastating pest of a variety of Kharif crops grown under rainfed conditions at elevations ranging from 600 to 2000 m ASL (Lal, 2018; Joshi and Kadiyal, 2007). Three species viz. A. dimidiata (Hope), $H$. longipennis (Blanch.) and H. seticollis (Moser) are predominant species in the state damaging almost all vegetables like cabbage, cauliflower, brinjal, tomato, capsicum, cucurbits, okra, pea, potato, garlic, rose, carnation, gladiolus, chrysanthemum and marigold grown during August-April (Singh et al., 2002). Anomala dimidiata (Hope) is a predominant species of white grub and distributed in Uttarakhand, Himachal Pradesh, Haryana, Punjab, Uttar Pradesh, West Bengal, Sikkim, Assam, Meghalaya and Manipur (Chandra and 
Uniyal, 2007). The bioecology of $A$. dimidiata (Hope) has been studied in Kumaun region of Uttarakhand by Garg and Verma (1993) and in Western Himalayan region by Mishra (2001) and Mishra and Singh (2006). Among all of these crops, sugarcane, maize, potato, and paddy are worst affected. The second and third instars grubs feed on roots and underground stems of the host plants. The losses incurred due to white grubs are huge in case of commercial crops like sugarcane, groundnut, potato, maize and upland rice (Ranga Rao et al., 2006). Biology of white grub Holotrichia longipennis (Blanch.) (Coleoptera: Scarabaeidae) in agricultural ecosystem, Doon Valley, (U.K.), India was reported by Sharma et al., 2019. In spite of its economic importance, no sufficient information is available on detailed biology of Anomala dimidiata (Hope), therefore, present study was carried out on the biology of $A$. dimidiata (Hope) under field conditions as well as in laboratory conditions.

\section{Materials and Methods}

Present study was carried out on the biology of $A$. dimidiata (Hope) under field conditions in sugarcane, maize and paddy crops as well as in laboratory conditions at Department of Zoology, D.A.V. (P.G.) College, Dehradun, during the year 2014-16.

Study Area: Present study was carried out in four different study sites of agricultural ecosystem of Doon Valley, Dehradun. It is located between latitudes $29^{\circ} 58^{\prime} \mathrm{N}$ and $31^{\circ} 2^{\prime} \mathrm{N}$ and longitudes $77^{\circ}$ $34^{\prime} \mathrm{E}$ and $78^{\circ} 18^{\prime} \mathrm{E}$. Climatically, study area shows three distinct seasons winter, summer and monsoon. Winter season continues from October to February. Days are moderate and nights are very cold with freezing frost during winter months. Summers are very hot with maximum temperature noticed was $41^{\circ} \mathrm{C}$ in day time continues from March to mid June. Monsoon season starts from mid June and continues till last week of September. The area surveyed in each site was 2 hectare. Detailed information about the upland rice and sugarcane crops of the study sites were collected.

Sampling, Preservation and Taxonomic Identification of Specimens: A light trap having 250 watt, milky bulb was installed at Doon Valley from May, 2014 to April, 2016 to record the peak period of emergence of beetles of $A$. dimidiata
(Hope). Random pit sampling were done in the sugarcane and rice field to record the intensity of population of various stages of $A$. dimidiata (Hope) starting from May, 2014 to April, 2016. Five pits $\left(1 \times 1 \mathrm{~m}^{2}\right)$ were dug out at a time in each month and average numbers of eggs / grubs / pupae / adults per pit were recorded out. During the active season i.e. from May to October, the sampling depth was kept $30 \mathrm{~cm}$, while during the inactive season (November to April) the depth was kept up to one meter. The adult insects thus trapped are collected in a small paper bag and collected in a bottle containing ethyl acetate soaked cotton. These insects brought to the laboratory for pinning and then oven dried at $60{ }^{\circ} \mathrm{C}$ for 72 hours in order to preserve them. The insects were separated into different species with the help of available keys. The insects, which could not be identified in the laboratory, were sent to Northern Regional Station of Zoological Survey of India, Dehradun and Entomological Section of Forest Research Institute, Dehradun for their identification.

Morphometric parameters of white grub beetles Ten eggs were selected randomly and measured for their length and width under high efficiency microscope. The larvae from each representative instars were randomly selected, killed and size of larvae was measured using digital Vernier Caliper $(0-150 \mathrm{~mm})$. The pupal and adult stage of beetle were also determined and measured using digital Vernier Caliper. The body of male and female adults were also measured from head to end of abdomen (Mari et al., 2004; Lal, 2018).

\section{Results and Discussion}

The light trap collections of scarab beetles, Anomala dimidiata (Hope) show that species belonging to Rutelinae is dominated in Doon Valley. The findings reveal that the emergence of beetle starts at the end of May but peak emergence was observed in the second and third week of July, 2015.

The data obtained on the biology of Anomala dimidiata (Hope) have been presented in Table-1.

(a) Mating Behavior: The males of $A$. dimidiata (Hope) show marked territorial behaviour and chase the intruding conspecific female. This beetle copulates in a normal manner i.e., the males hold 
the elytra of female and the female carries him. The observed copulation period was $40.0 \pm 14.14 \mathrm{~min}$.

(b) Oviposition: A female laid $26.5 \pm 2.12$ eggs during her life time. The male release the grip on female prothorax after the completion of oviposition. Oviposition period was $8.0 \pm 1.41$ days.

(c) Life-stages: The species complete its life cycle through 4 stages as mentioned below:

(i) Eggs: The size of freshly laid eggs was measured from $1.79 \pm 0.02$ in length and $1.31 \pm 0.01$ $\mathrm{mm}$ in width. Eggs are elongated, cylindrical and laid in clusters. The observed incubation period was of $14.60 \pm 0.72$ days.

(ii) Larval development: In the early instars, larvae were fed on host plants (sugarcane, maize, paddy).

I $^{\text {st }}$ Instar: Elongate fusiform. $10.91 \pm 0.19 \mathrm{~mm}$ long and $1.71 \pm 0.04 \mathrm{~mm}$ in averaged width, respectively. The body was whitish in color and changed to creamy white within a short period. Head capsule, thorax and abdomen distinguished clearly. This stage lasts for $23.4 \pm 0.45$ days.

II $^{\text {nd }}$ Instar: Creamy white bodied elongated within a short period. The body measured $22.64 \pm 0.22 \mathrm{~mm}$ in length and $3.59 \pm 0.05 \mathrm{~mm}$ in width. This stage lasts for $33.60 \pm 0.56$ days.

III ${ }^{\text {rd }}$ Instar: Body elongated, $34.76 \pm 0.32 \mathrm{~mm}$ long, $5.23 \pm 0.16 \mathrm{~mm}$ broad, body is creamy white, though the head is brown, gradually thick and C-shaped body. This stage lasts for $213.50 \pm 0.69$ days.

(iii) Pupa: The pupa was measured to $22.19 \pm 0.29$ $\mathrm{mm}$ long and $10.91 \pm 0.21 \mathrm{~mm}$ broad, creamy-white, dorsum roughly convex, abdomen slightly yellowish, with segmented body. This stage lasts for $14.70 \pm 0.62$ days.

(iv) Adult:

Female: The female is broadly oval, less convex shape, medium sized about $20.88 \pm 0.19 \mathrm{~mm}$ long and $11.21 \pm 0.19 \mathrm{~mm}$ broad across the middle elytra. The upper surface is apple green with metallic texture when the lower surface and legs are bluish green. This stage lasts for $31.10 \pm 0.98$ days.

Male: The male also is broadly oval, less convex shape, medium sized about $18.62 \pm 0.14 \mathrm{~mm}$ long and $10.34 \pm 0.24 \mathrm{~mm}$ broad. The upper surface is apple green with metallic texture when the lower surface and legs are bluish green. The ventral and lateral surfaces are thoroughly covered with reddish hairs. This stage lasts for $24.40 \pm 0.69$ days.

Mishra and Singh (2006) made the similar observations about A. dimidiata (Hope) and observed an average pre-oviposition and oviposition period as 4.10 and 13.20 days. Garg and Verma (1993) have observed the body length in IIII instars that were about $14 \mathrm{~mm}, 20-22 \mathrm{~mm}$ and $37.5 \mathrm{~mm}$ and the time duration were $8-18,35-42$ and 233-261 days, respectively. Pathania (2014) also observed the body lengths in three instars of this species are about 10-12, 23-25 and 35-40 mm and the time durations were $23-26,30-37$ and $210-$ 220 days, respectively. The pupal period ranged 17.5-18.7 days for this species was reported by Mishra and Singh (2006) and Garg and Verma (1993). Garg and Verma (1993) also observed approximately similar description for adult beetles of $A$. dimidiata (Hope) from hill part of Kumaun (Uttarakhand).

Table-1. Biology and development of different stages of $\boldsymbol{A}$. dimidiata (Hope) on host plants

\begin{tabular}{|c|c|c|c|}
\hline Life stages & $\begin{array}{l}\text { Duration in days } \\
(\text { Mean } \pm \mathrm{SE})\end{array}$ & $\begin{array}{l}\text { Length }(\mathrm{mm}) \\
(\text { Mean } \pm \mathrm{SE})\end{array}$ & $\begin{array}{l}\text { Width (mm) (Mean } \pm \\
\text { SE) }\end{array}$ \\
\hline Egg & $14.60 \pm 0.72$ & $1.79 \pm 0.02$ & $1.31 \pm 0.01$ \\
\hline I instar & $23.4 \pm 0.45$ & $10.91 \pm 0.19$ & $1.71 \pm 0.04$ \\
\hline II instar & $33.60 \pm 0.56$ & $22.64 \pm 0.22$ & $3.59 \pm 0.05$ \\
\hline III instar & $213.50 \pm 0.69$ & $34.76 \pm 0.32$ & $5.23 \pm 0.16$ \\
\hline Pre-pupal stage & $13.70 \pm 0.46$ & - & - \\
\hline Pupa & $14.70 \pm 0.62$ & $22.19 \pm 0.29$ & $10.91 \pm 0.21$ \\
\hline Total time duration & $313.5 \pm 3.53$ & - & - \\
\hline Adult longevity Male & $24.40 \pm 0.69$ & $18.62 \pm 0.14$ & $10.34 \pm 0.24$ \\
\hline Female & $31.10 \pm 0.98$ & $20.88 \pm 0.19$ & $11.21 \pm 0.19$ \\
\hline
\end{tabular}


The finding thus suggests that $A$. dimidiata (Hope) is most destructive pests of Sugarcane, maize and paddy crops. Beetles of $A$. dimidiata (Hope) defoliate the various fruit/ forest trees and some wild shrubs, while the grubs, which are subterranean in habit, damage almost all the rainy season crops grown under rainfed condition. Among all of these crops, sugarcane, maize and paddy are worst affected, both in Doon Valley. The second and third instar larvae move up to feed upon roots much nearer the surface. The larvae in the soil feed on live roots, rootlets and underground stems of the host plants. This being the longest and most destructive stage, the infestation leads to initial yellowing, stunted growth and subsequent drying and wilting of plants. The severity of their damage has resulted in reduction of area under these crops in the region of Doon Valley and the farmers have become reluctant in growing these crops.

\section{Conclusion}

Being the phytophagous nature, high species diversity and diverse feeding habit of immature and adult stages, management of white grubs is a very tough task. As the white grubs infestations is more striking in high altitude crops, where the farmers are very poor and having minimum resources, the eco-friendly practices likecrop rotations, deep ploughing after crop harvesting, and cover crops

\section{References}

Chandel, R. S. and Kashyap, N. P. 1997. About white grubs and their management. Farmer and Parliament, 37: 29-30.

Chandel, R. S., Pathania, Mandeep, Verma, K. S., Bhattacharya, Badal, Vasishta, Sumit and Kumar, Vinod. 2015. The ecology and control of Potato white grubs of India. European Association for Potato Research, 58: 147-164.

Chandra, Kailash and Uniyal, V. P. 2007. On a Collection of Pleurostic Scarabaeidae (Coleoptera) from the Great Himalayan National Park, Himachal Pradesh, India. Zoos Print Journal, 22(9): 2821-2823.

Garg, D. K. and Verma, P. V. 1993. Bionomics of white grub, Anomala dimidiata (Hope) in Kumaon hills, Uttar Pradesh II. Journal of Soil Biology and Ecology, 13(2): 136-143.

Jameson, Mary, Liz and Ratcliffe, Brett, C. 2001. Scarabaeoidea: Scarabaeid beetles (=Lamellicornia) (URL: http://www.museum.unl.edu/ research/ entomology/ Guide/ Scarabaeoidea/ Scarabaeoidea-pages/ Scarabaeoidea- may be used for the management of this pest. The other methods of IPM that include entomopathogens, bio-pesticides, seed treatment, soil application and application of pesticides can be followed to overcome the white grub threats. This study also indicates that major sugarcane growing belt and other crops like maize, paddy and potato growing areas were highly infested. So, there is an urgent need to control the white grub infestation of commercial crops at larval stage and host plants at adult stage. Understanding the biology of $A$. dimidiata (Hope) is therefore, essential for developing effective management strategies and undertaking control operations by farmers. A better planning is needed for early detection and reporting of infestations/ spread of new pest species by establishing communication links between taxonomists, ecologists and local farmers to monitor and control.

\section{Acknowledgement}

Authors express his gratitude to (Late) Prof. P.C. Joshi, Ex. Head, Department of Zoology and Environmental Sciences, Gurukul Kangri University, Haridwar, India, for giving valuable suggestions. We are also thankful to (Late) Dr. R.K. Jauhari, Ex. Head, Department of Zoology, D.A.V. (P.G.) College, Dehradun for providing the necessary facilities.

Overview/ScarabaeoideaO.html). In: B.C. Ratcliffe and M. L. Jameson (eds.), Generic Guide to New World Scarab.

Joshi, G. C. and Kadiyal, V. K. 2007. Bio-ecology of white grub Holotrichia longipennis (Blanch.) on off-season vegetables in Garhwal hills of Uttarakhand. Himyalayan Journal of Environment and Zoology, 21(1): 109-111.

Lal, Mukesh. 2018. In: Ph.D. thesis "Biodiversity and ecology of white grub in agriculture and forest areas of Doon Valley, Uttarakhand." Submitted to H.N.B. Garhwal University, Srinagar Garhwal.

Lal, Mukesh and Sharma, P. K. 2017a. Species composition and abundance of white grubs (Coleoptera: Scarabaeidae) in agricultural ecosystem of District Dehradun (Uttarakhand), India. Journal of Environment and BioScience, 31(2): 447-452.

Lal, Mukesh and Sharma, P. K. 2017b. Species richness and abundance of white grubs (Coleoptera: Scarabaeidae) in forest ecosystem of District Dehradun (Uttarakhand), India. Journal of Environment and BioScience, 31(2): 301-305. 
Mari, J. M., Nizamani, S. M., Lohar, M. K. and Khuhro, R. D. 2004. Biology of Menochilus sexmaculatus (Fab.) and Coccinella undecimpunctata (L.) (Coccinellidae: Coleoptera) on Alfalfa Therioaphis trifolii Monell. Journal of Asia-Pacific Entomology, 7(3): 297-301.

Mishra, P. N. 2001. Scarab fauna of Himalayan region and their management. In: Indian Phytophagous scarabs and their management: present status and Future strategies. Agrobios (India), Jodhpur, pp. 74-85.

Mishra, P. N. and Singh, M. P. 2006. Biological observations on white grub, Anomala dimidiata (Hope) (Coleoptera: Rutelinae) in Western Himalaya. Indian Journal of Entomology, 69(2): 113-116.

Pathania, Madeep. 2014. Studies on phytophagous white grubs of Himachal Pradesh. Ph.D. Thesis, CSK Himachal
Pradesh Krishi Vishwavidyalaya, Palampur, (H.P.), India. pp. 1-258.

Ranga Rao, G. V., Ngo Thi Lam Giang, Phan Lieu and Nguyen, Thi Hoai Tram. 2006. Occurrence of White Grubs in Groundnut Crop in Uplands of South Vietnam: A new report. $\boldsymbol{I} \boldsymbol{A} \boldsymbol{N}, 26: 45-48$.

Sharma, Pushpendra K., Lal, Mukesh and Joshi, Prakash Chandra. 2019. Biology of white grub Holotrichia longipennis (Blanch.) (Coleoptera: Scarabaeidae) in agricultural ecosystem of Doon Valley (Uttarakhand), India. Journal of Environment and BioScience, 33(1): 159-162.

Singh, S. S. Mishra, P. N. and Nainwal, N. C. 2002. Status and management of white grub (Coleoptera: Scarabaeidae) in horticultural crops. Progressive Horticulture, 34(1): 6-16. 